\title{
El Perú de Mariátegui: detenidos en el tiempo y el despertar de una era
}

\author{
Mariáteguip Pirukaanin:pachakaaćhu \\ śhaykuśha huk irap lichkayninwan
}

\section{Ora Peró ipaña mariategi:kantanëro kengagantsi kaninaro}

Recibido: 29 febrero $2020 \quad$ Aprobado: 28 marzo 2020

\author{
Franklin Américo Canaza-Choque \\ Nacionalidad: Peruana \\ Filiación: Universidad Católica de Santa María, Perú \\ Correo:franklin.canaza@ucsm.edu.pe \\ ORCID: http://orcid.org/0000-0002-1929-6054
}

\section{Resumen}

En el intento supremo de revelar en Perú aquellos motores de impulso que permitieron a los subterráneos poner en marcha y dinámica el curso evolutivo de los primeros años de la historia republicana del siglo XX. El interés parte de argumentar, alrededor de otros, algunas aristas del impacto que significó para los lectores del dueño de los 7 ensayos el comportamiento de una etapa histórica más ajustadamente a finales del XIX e inicios del XX, como dos periodos de ruptura y síndrome de parálisis socio-emocional dejados por la Guerra del Pacífico (1879-1883); pero al mismo tiempo, de movimiento civilizatorio de impugnación, resistencia y construcción nunca antes vistos y articulados colectivamente por efectos sobrevenidos de la penetración de las primeras e incipientes energías capitalizadoras foráneas en el territorio peruano y del que fue pieza clave de ese resistir indómito, José Carlos Mariátegui (1894-1930).

\section{Palabras clave:}

Aristocracia, guerra, historia, capitalismo, Perú.

\section{Lisichiku limaykuna:}

Kalakay, maanakuy, lulaytaway, illaykaap.Piru.

\section{Nibarintsipage katingatsaro:}

asintaarontacha, ogobagantsi, kengabagetagantsi, kiregiberijegi, Peró.

\section{Datos del autor}

Docente-Investigador Social en Materia de Derecho Procesal y Administración de Justicia por la Universidad Católica de Santa María [UCSM]. Magíster en Administración Educativa y Licenciado en Educación Secundaria con Mención en la Especialidad de Ciencias Sociales por la Universidad Nacional del Altiplano [UNA]. 


\section{Mariátegui's Peru: Detainees in The Time and The Awakening of an Era}

\begin{abstract}
In the supreme attempt to reveal in Peru those engines of momentum that allowed to the underground set in motion and dynamic evolution of the first years of the republican history of the twentieth century. The interest is based on to argue, around others, some edges of the impact that meant for the readership of the proprietor of the 7 essays the behavior of a historical stage more tightly in the late 19th and early 2oth centuries, as two periods of rupture and socio-emotional paralysis syndrome left by the Pacific War (1879-1883); but at the same time, of civilizatory movement of challenge, resistance and construction never before seen and articulated collectively by the supervened effects of the penetration of the first and incipient capitalizing energies in the Peruvian territory and of which it was a key piece of that untamed resistance, José Carlos Mariátegui (1894-1930).
\end{abstract}

\author{
Keywords \\ Aristocracy, war, history, \\ capitalism, Peru.
}

\section{O Perú de Mariátegui: detidos no tempo e o despertar de uma era}

\section{Resumo}

Na tentativa suprema de revelar no Peru aqueles motores de impulso que permitiram aos "subterrâneos" pôr em andamento e dinâmica o curso evolutivo dos primeiros anos da história republicana do século XX. O interesse parte de argumentar, ao redor de outros, algumas arestas do impacto que significou para os leitores do dono dos 7 ensaios, o comportamento de uma etapa histórica mais de perto até o fim dos séculos XIX e inícios do XX, como dois períodos de ruptura e síndrome socioemocional de paralisia deixado pela Guerra do Pacífico (1879-1883); mas, ao mesmo tempo, de movimento civilizatório de impugnação resistência e construção nunca antes vistos e articulados coletivamente por efeitos vindos da penetração das primeiras e incipientes energias estrangeiras que se capitalizaram no território peruano e do que foi peça chave de esse resistir indômito, José Carlos Mariátegui (1894-1930).

\section{Palavras-chave:}

Aristocracia, guerra, história, capitalismo, Peru. 


\section{Introducción}

A finales del siglo XIX e inicios del XX, en la historia del Perú, algo no andaba bien. República Aristocrática (1895-1919) denominaría Jorge Basadre Grohmann (1903-1980) a un fragmento de la historia en el que dominaba una oligarquía heterogénea que concentraba el poder político, el dominio económico y el control por sobre la superficie social. Eran esos años, llenos de disensiones, clases sociales, minorías, de partidos políticos modernos, y además de estar cuajado de importantes intelectuales de era, una época que detrás y dentro de esa arquitectura poco formada, algo parecía ser extraño.

En los días en que González Prada escribía de manera idílica y como si fuese una composición literaria, el Perú había llegado hasta cierto punto a estancarse en el tiempo: las resonancias de la Guerra del Pacífico (1879-1883) y la Guerra Civil de los denominados "rojos" y "azules" (1884-1885) ahondaban en la vida de muchos habitantes de ese entonces. El Estado tendía a desvanecerse en su propia lógica de resguardar a su gente, el sentido de patria y nación representaban ser un vacío y algo confuso para muchos, pues este, aún no había llegado al corazón del indígena y de una clase media emergente. En esa atmósfera, no era de extrañar que el Perú profundo -aquel espacio social del que poco se hablaba en la vida política de ese entonces- se alejaba del proyecto de República, eran entonces, tiempos nostálgicos según se cuenta en la literatura nacional (Galindo, 1980). Envueltos y a la vez penetrados emocionalmente por cargas inconsolables y de sentimientos desoladores por aquellas tragedias estructurales de historia.

Entre esas conmociones, la inserción del capitalismo norteamericano comenzó sus primeras contracciones y formas de expansión embrionaria, se fracturaron las antes sólidas alianzas políticas, se empezó a desplazar a un Estado deleznable de la carrera económica y como fuerza re-configuradora de aquella dimensión político-social. De manera que se asistió a un desarme de la plataforma estructural; pero también, a mediano y largo plazo, el carácter con el que se expresaba esta poderosa fuerza de modelo económico provocaría años después, sus primeras sacudidas en el sistema derivadas de un despertar y retorno indígena en la lucha por la tierra en contra de aquellas grandes haciendas que habían acaparado su dominio sobre esa fuente espacial.

En la costa, no era de extrañarse los primeros remesones y signos de inestabilidad y convulsión social producto de una clase baja-media emergente que pugnaba por mejores salarios y condiciones de vida a efectos del propio desarrollo capitalizador en las riberas del mar del Pacífico. Fue entonces que, podría decirse que los proletariados -incipientes- de un Marx (1818-1883) ya fenecido en vida, seguirían su destino en aquellas tierras peruanas a principios del siglo XX. Pero esta vez, anexados a una idea de lucha más clara, el que precisamente se encontraba en el corazón de José Carlos Mariátegui (1894-1930).

En ese intento supremo de revelar aquellos motores de impulso que permitieron a los subterráneos poner en marcha y dinámica el curso evolutivo de los primeros años de la historia republicana del siglo XX. El interés parte de argumentar, alrededor de otros, algunas aristas del impacto que significaba para los lectores del dueño de los 7 ensayos el comportamiento de una etapa histórica más ajustadamente a finales del XIX e inicios del XX como dos periodos de ruptura y síndrome de parálisis socio-emocional dejados por la Guerra del Pacífico; pero al mismo tiempo, de movimiento civilizatorio de impugnación, resistencia y construcción nunca antes vistos y articulados colectivamente por efectos sobrevenidos de la penetración de energías capitalizadoras foráneas en el territorio peruano y del que fue pieza clave de ese resistir indómito, José Carlos Mariátegui. 


\section{Criterio metodológico}

Para efectos de este estudio, el cuerpo metodológico reviste su principal línea de investigación argumentativa en el marco del enfoque cualitativo, basado en la investigación documental y bibliográfica de referentes que permitieron mantener aún, una re-interpretación de varios desafíos teóricos y prácticos poco desplegados sobre los terrenos y denominadores del pasado republicano.

Este muestreo teórico posicionó tres puntos. Primero, se definió el contexto en el que principalmente sucedieron los hechos históricos, más exactamente, durante el periodo de la República Aristocrática (1895-1919). Las primeras fechas de su inicio aun contemplaron en la sociedad peruana de esos años las dilaciones emocionales de la derrota nacional en la Guerra del Pacífico (1879-1883), pues este último significó -según el artículo tercero del Tratado de Ancón- el posicionamiento territorial de Tacna y Arica durante el lapso de 10 años dentro de la soberanía chilena. No fue hasta 1929 con el Tratado de Lima que terminó por anexar definitivamente Arica en la administración de las ligas patrióticas chilenas y la reincorporación legal de Tacna a Perú, sucesos que acabaron con aquellas tensiones bilaterales motivadas por el control de la industria salitrera y de fuertes relaciones comerciales con enérgicas potencias extranjeras.

El segundo punto, posiciona más claramente a dos personajes que se incrustaron a través de una sustancial reflexión intelectual en aquel trayecto del periodo aristocrático. El primero de ellos, Manuel González Prada (1848-1918), que, en efecto, luego de la guerra era algo normal y muy común en los intelectuales rebuscar a los verdaderos responsables de aquella catástrofe nacional. Para el anarquista y poeta peruano, aquel fracaso estuvo localizado dentro del espíritu social y de la irrisoria libertad del indio. Pues este problema tuvo una dimensión más allá de solo ser pedagógica, sino también económica y social.

En tanto que el segundo, al que se prestó una profusa atención, fue el pensador marxista de continuidad histórica, José Carlos Mariátegui, que dentro de su obra capital los 7 ensayos de interpretación de la realidad peruana, este estaciona como el centro de todas las ansiedades y de dolor histórico al indio, que no solo se alojaba como problema social y económico, sino, además, su figura estaba asociado al problema de la tierra y el poder de ser sometido por fuerzas proscribes. Así, para el teórico-marxista peruano, la redención indígena y de una clase proletarizada tienen un solo camino, ponerle fin al sistema de producción explotador de aquellos años. Son por debajo de esas propiedades que Mariátegui desdobló en vida una incansable teorización de soporte y argumento sólido para las denominadas fuerzas venidas desde abajo. De ahí, su importancia en el ahora y del más allá de este. Pues su pensamiento permite decolonizar y emancipar la historia del nosotros y de los otros de un poderoso sedimento colonial acarreado durante años.

Como último punto, con la finalidad de profundizar y poner en dinámica las visiones del pasado, el abastecimiento de este ensayo científico, muy aparte de que mantenga una carga documental histórica de origen descriptivo, también distingue aportes críticos de otros autores que giraron alrededor del pensamiento mariateguiano y de aquella etapa histórica. Sin que esto parezca cerrar la investigación a una sola línea o de hacerla obstruir en un camino más amplio, igualmente tuvo un análisis global de otros estudios decodificados en indizadores puestos en línea como Scopus, Web of Science y SciELO. Ensamblándose a ellos, otros canales digitales que afianzaron una construcción más razonada y libre (Canaza-Choque, 2018a; 2018b; 2018c; 2019a; 2019b; 2020; Canaza-Choque y Huanca-Arohuanca, 2018; Huanca-Aro- 
huanca y Canaza-Choque, 2019). Finalmente, dentro de este mismo punto, se realizó un balance final a modo de conclusión que, por cierto, no se capitula a ser el último ni mucho menos el definitivo.

\section{Mistificación}

Una primera advertencia: "mi pensamiento y mi vida constituyen una sola cosa, un único proceso [...]" (Mariátegui, [1928] 2007, p. 5). En la sólida y gruesa interpretación del compositor peruano César Miró-Quesada (1989), José Carlos Mariátegui enterró toda su sangre en sus ideas, conforme a un principio encarnado en Nietzsche, porque tenía una convicción fija y una fe inquebrantable, una declara y enérgica ambición poderosa: la de concurrir a la creación del socialismo peruano.

Se ha leído a Mariátegui desde infinidad de ángulos y terrenos disciplinarios (Gomes, 2007), y esta no es una excepción casual, y es que Mariátegui se ha situado y convertido a lo largo de los años en el centro sísmico de donde "parten diferentes opiniones, muchas de ellas opuestas y antagónicas" (Escobedo, 2014, p. 23). De eso, no existe y queda la menor duda. Esta claro que el manejo teórico-reflexivo y el discurso del que posee Mariátegui están muy lejos de formar y ser parte de un debate plenamente acabado y detenido en el tiempo ( $D^{\prime} A^{\prime}$ llemand, 1994).

En tal sentido, siguiendo el patrón de una de las más condensadas enseñanzas y formulaciones del pensamiento marxista, y como menciona Javier Mariátegui (1928-2008), la expresión favorita del Amauta de las Tesis sobre Feuerbach de Marx: "los filósofos no han hecho otra cosa que interpretar el mundo de diversas maneras, pero de lo que se trata es de transformarlo" (Mariategui, Flores Galindo y Portocarrero, 1989, p. 14). Bajo esa persuasión imperiosa y heredera de gran transforme social y filosófico, quienes desde las Ciencia Sociales y los estudios humanos bregan, están condenados a seguir ese paradigma. Esto, no significa ser la única salida de poder transfigurar lo fáctico; pero sí, una de las formas más poderosas del pensamiento incrustado en Marx y de sus lectores al momento de acercarse a lo real y de transformarlo.

Como si esta escena fuera ya conocida, "Mariátegui sabía que él no tenía mucho tiempo, que él tenía que trabajar rápido. Sus logros en el corto período de treinta y cinco años son nada menos que asombrosos" (Stein, 2007, p. 5). Ya que después de haber recorrido y leído en fragmentos el espíritu completo de Europa, a fines de 1923, es un Mariátegui distinto el que retorna a su país, uno totalmente diferente del que alguna vez había partido desde aquella tierra precaria que lo reclamaba como suyo (Guibal e Ibáñez, 1987).

Todo un convicto y confeso marxista atravesado por el tiempo y el espacio que le tocó transitar, Mariátegui regresa con motores sensibles, su mujer y su primer hijo, son ahora los impulsos para seguir desafiando el futuro. El temor y el escepticismo han quedado atrás, más exactamente, en los caminos de la vida cuando se es joven: el escritor se ha convertido en un luchador social y el máximo vanguardista de la clase proletariada en Perú. Aunque este, no lo sepa claramente, sólo le quedan siete años de vida. En ese breve lapso fundará la revista Amauta (1926), el Partido Socialista (1928), la Confederación de Trabajadores del Perú (1929), y entre otros y estos publicará además su mayor legado interpretativo puesto en la agenda académica de los años ulteriores a su existir: los "7 ensayos de interpretación de la realidad peruana" (1928) (Ramos, 1973). Toda esta creación, -aunque no estaría bien decirlo de esta 
manera-con un solo propósito múltiple: emancipar, sindicalizar, articular e integrar el Perú en general, de interpretar, repensar y transformar el otro Perú en particular.

"Nuestro autor fue un crítico de su tiempo" y del que ahora se habla (Flores, 2013, p. 25), su vigencia, destino y legado intelectual y político de José Carlos fue especialmente curioso (Guibal e Ibáñez, 1987; Mariátegui J. C, 2010). Días después a su muerte, este "fue seguida por una transformación del instrumento político que había creado, de Partido Socialista a Partido Comunista, afiliado a la Komintern. De hecho, durante la década del treinta el propio Partido Comunista Peruano (PCP) rechazó la herencia mariateguiana, caracterizada como 'populista' [y poco radical]" (Mariátegui ]. C., 2010, p. 25).

En esa tensa situación, el PCP y la Internacional Comunista bajo la dirección de Eudocio Ravines (1897-1979) terminaron por derrotar a un ya fallecido J. C. Mariátegui (Adrianzén, 2011). En esa odisea, de si el pensamiento seguía o no, "la progresiva difusión [del espíritu de los 7 ensayos por parte de Sandro] fue llevando a su revaloración, no exenta de actitudes oportunistas. [Pues] durante décadas, diferentes sectores del espectro político peruano se han definido como los auténticos herederos del legado mariateguiano. [...] la contemporaneidad de esa obra: es notable en Mariátegui su capacidad para acompañar su tiempo [y en el tiempo] (Mariátegui J. C., 2010, p. 25). “Su muerte prematura [...] conmovió al mundo intelectual, obrero y campesino peruano, y desde entonces su fama comienza a ser universal conforme transcurren los años" (Mariátegui J. , 1997, p. 7), su pensamiento recorre escenarios antes poco o nunca percibidos, y en especial, Latinoamérica, el de la simbiosis del indigenismo y el socialismo oriundo.

Es un hecho que "hasta el fin de su vida, Mariátegui guardo consigo, al lado de la liberación de la clase obrera y de su país, las ideas de libertad para todos los pueblos. Perseguido desde hacía tiempo por las sombras de la muerte, completó su destino histórico el 16 de abril de 1930" (Melis, Dessau y Kossok, 1971, p. 147). Como a todos los mortales, la tierra lo esperaba, y que pese a ser atrapado por quien lo vio germinar y consumido por esta misma, aun flotaban átomos de su propio pensamiento en el aire.

Es entonces, en todas las temporalidades, José Carlos el punto de partida de la política y la filosofía en el Perú, como Guibal e Ibáñez (1987, p. 7) mencionan: "hoy en día, casi, esta demás decirlo, se puede observar que prácticamente la totalidad de las corrientes de izquierda de nuestro país se consideran herederas de su legado". Sin embargo, parafraseando la quinta idea del profesor del Departamento de Ciencias Sociales de la Pontificia Universidad Católica del Perú (PUCP), Augusto Castro (2006), el que el socialismo no haya logrado vertebrar una poderosa e inquebrantable fuerza unida, fraterna y de solidaridad consigo mismo y con el país no es responsabilidad de Mariátegui, que propugnaba la vitalidad, la energía y el sentido creador del socialismo. Concluyendo que "no ha existido movimiento más dividido y sectario que la izquierda" y que la política y su debacle en el Perú en estos últimos años y décadas no es responsabilidad de este hombre que solo quiso acabar y demoler esos muros que impedían erigir sociedades más democráticas, justas e igualitarias (Castro A., 2006, pp. 21-22).

Desde esas razonadas, "para incontables peruanos, Mariátegui ha sido un ancla, una fuente de fortaleza y coraje, una lumbrera, una luz, que alumbra la justicia que vendrá" (Stein, 2007, p. 13). De tal manera que, si su importancia radica en uno que va más allá de solo ser un pensamiento englobante y quedarse en esa misma naturaleza, entonces, no habría justificación alguna del por qué no releer y repensarlo ahora más que nunca de una forma que no sea la misma cada vez que se le quiera ver en el orden actual o de invocar fuera del pensamiento. 
Dentro de esa misma órbita, es posible liberar dos interpelaciones que bien fijarían su trascendencia. La primera, con una consideración más grande y de tratamiento especial, ¿Cómo se inmortalizó aquel hombre que escribió los 7 ensayos? Pregunta clave del que en resumidas formas se ha intentado alrededor de sus herederos e implícitamente traspuesto en fragmentos anteriores que permitan datar sobre algunos puntos nucleares de por qué Mariátegui sigue estando en medio de todas las discusiones contemporáneas y de las que se puedan seguir independizando en el campo político-económico, socio-cultural y educativo, sin que esto signifique el de no llegar a otras zonas y esferas del terreno humano. Pues el Amauta, como se le recuerda en cada enseñanza que se hace, ha llegado no solo por enraizarse más plenamente en los horizontes de los años 20 del pasado siglo; sino que además, ha logrado con una promesa moderna de convicción de atravesar el tiempo, en una era en donde se somete a prueba todos aquellos logros y dilemas inacabados de su pensamiento crítico autonómico.

La segunda, conduce en el mismo sentido prospectivo, si Mariátegui es en forma clara la otra manera de pensar y repensar una faceta del tiempo actual, en el que prácticamente todos los ámbitos de la vida humana han tornado ser irreconocibles, una pregunta que se ajusta al tópico es: ¿Cómo volver a releer y entender a Mariátegui en un tiempo de alta presión en el que los avatares de la globalización y la posmodernidad se tornan más agresivos que antes? Tanto la primera como la segunda -que por efectos del estudio no serán tratadas ahora- vienen a ser provocadoras e inquietantes cuestiones, como muchas de las que libera y plantea Aníbal Quijano (2012) dejando en claro para la reflexión profunda sobre:

¿Quién era, en verdad, ese José Carlos Mariátegui cuya paternidad lo habitaba y que, aunque no estuviera a su lado, estaba con él? ¿Cuál era el movimiento de su reflexión, cuales cuestiones, ideas, propuestas eran las suyas y que lo hicieron el amauta de la leyenda y de la historia del Perú? ¿Cómo fue que un niño pobre, lisiado, sin padre y sin educación escolar llego a ser ese José Carlos Mariátegui? ¿De cuál fuente interior brotaba, a pesar de todo y contra todo, la alegría que, según todos los testimonios, lo sostenían en todas las circunstancias y que chispeaba como esperanza sobre todos los que estaban con él? (Quijano, 2012, p. 13).

De igual manera, para reforzar la nota anterior, como cita el sociólogo Osmar Gonzales (2011, p. 57), "nadie podía sospechar que ese jovencito esmirriado [...], se convertiría con el tiempo en el pensador social más importante que ha dado el Perú" y que dentro -según Tarazona (2011, p. 111)- de los escasos "pensadores que ha dado América Latina, aquellos que han sobrevivido a su época y siguen señalando derroteros para el desarrollo de la cultura, incluso provocando polémicas, señal de vitalidad, se encuentra José Carlos Mariátegui".

\section{Detenidos en el tiempo y el despertar de una era}

Hace poco más de 50 años, para el filósofo peruano Augusto Salazar Bondy (2016), la cultura, tal como se la entendía había llegado, al menos por un instante, detener su respiro frente a las grandes metáforas del tiempo. El contenido de unidad e integridad se evaporizaban a falta de un potencial que pueda congregar a la sociedad en un mismo sentido y de alcanzar los sueños de aquella anhelada República de convertir al Perú en un país próspero, moderno y europeo. A todo ello, las corrientes y doctrinas -como el cientificismo moderno y el espiritualismo- habían fallado en la constitución y promesa de un sentimiento de nacionalidad; por un momento, daba la sospecha de que la sociedad peruana del siglo XX se había estancado en sus primeros inicios de la historia, y de ella, era poco probable moverse de nuevo o de reiniciar su partida. Aquí, el pesimismo y la resignación nacían y se alimentaban como consecuencia de los 
horizontes estrechos y de la falta de perspectivas en el proyecto país y de las fallas históricas que la escoltaban (Galindo, 1980).

Durante esos años, el moqueguano tenía “la expectativa de un Perú en el que nadie deseara ser un capitalista. ¿Imposible? En su siglo y en el actual, sí; pero entonces Mariátegui siempre consideraba la posibilidad de lo imposible" (Stein, 2007, p. 27). Pues entonces, ¿Cuál era esa peripecia de lo improbable en un periodo en donde todo parecía estar detenido y ajustándose a las primeras miradas de un capitalismo foráneo? ¿Qué le motivo a dejarlo todo a cambio de nada y de encontrar en ello los nuevos motores para iniciar la partida de una historia ya estancada? Tal vez aquella visión ya confesada antes; quizás la lógica y los principios progresistas que lo acompañarían toda su vida; probablemente aquella esperanza super-humana, el mito o tal vez la posibilidad de encontrar, y de si no hallarlo, de construir el otro mundo posible sea como fuese.

Para Alberto Flores Galindo (1980), en los años en que Mariátegui realizó su iniciación literaria. Eran años tediosos absorbidos y devorados por el apogeo de la República Aristocrática, eran días epocales llenas de fragmentos dispersos, poco construidos y otros destruidos. Lo único que bien podría decirse de aquellos años y que tenía forma, era que gran parte de los intelectuales jóvenes compartían una actitud de pesimismo y resignación ante los problemas peruanos y de los que habían sido acarreados en el camino de la historia republicana.

Se negaba el pasado y especialmente a la generación anterior [...]. La sociedad era tan gris como el cielo de Lima y la melancolía era incluso cultivada con esmero por los escritores: Juan Croniqueur había pensado precisamente titular a su primer poemario con el lacónico nombre de Tristeza. [...] El pesimismo era compatible con una imagen pasiva y resignada de los campesinos: se ignoraban los gestos de rebeldía de la masa indígena [...]. En los textos científicos como en las obras de ficción se mostraba no sólo la imagen de un país atrasado y pobre, sino también un conjunto de actitudes que nacían de la condición de vencidos heredada desde la conquista. [...] a esa frustración se añadiría tiempo después otra mayor, consecuencia de la derrota militar de 1879: la ocupación del territorio y el colapso económico. Podía suponerse, con todos estos antecedentes, que el Perú no era una nación y que el proyecto de la república había fracasado [...]. (Galindo, 1980, p. 39).

Si bien Galindo entre su prosa nos relata una especie de rechazo sentimental hacia aquellos años que se alejaban del presente y que la responsabilidad más grande caía exactamente, en quienes se habían encontrado con esa carga temporal. Era entonces, que la imagen captada y que se tenía de ese Perú a finales del siglo XIX e inicios del XX, eran escenarios abatidos por enormes fuerzas reales y espectrales en el que las emociones jugaban en contra de la capa social; y que dentro de esa imagen detenida, la resignación fue el papel categórico de una gran parte de los peruanos que se encontraban en la condición de vencidos de un pasado colonial doloroso al que años después se agregaría en el recorrer histórico, la Guerra del Pacífico como punto de quiebre que por su impacto remeció los cimientos del futuro al hacer estallar las estructuras sociales de la precaria condición en Perú.

Escenario pictórico del '79 que congregó y mezcló, por un lado, una serie de decisiones y circunstancias de acción patriótica, especialmente, de sectores populares y de otros poco visibles. Mientras que, por otro lado, todas las narraciones que devenían de la guerra con Chile, estaban casi siempre acompañadas de desprecio, frustración y amargura hacia una casta política de envergadura nacional debido a que el fracaso se debió con mayor peso capital en la desunión de las fuerzas políticas durante el desarrollo del conflicto bélico que cambió el 
rumbo de la idea de que en el sur se encontraba un distante, pobre y pequeño territorio sureño Ilamado Chile.

Después de un desmoronamiento del Estado y del riesgo de su absoluta desintegración soberana-territorial como consecuencia de la derrota en la Guerra del Pacífico, que, por cierto, fue un hecho que terminó con pérdidas devastadoras en merced del enemigo, Chile, repercutió como si fueran ondas interminables "a través de todo el espacio peruano y desencadenó una serie de remezones, entre ellos el derrumbe financiero, la pérdida territorial, el levantamiento social y la guerra civil. No es de sorprender que una de esas secuelas" fuera una masiva insurrección indígena en 1884 y de las otras que devendrían posteriormente (Klarén, 2007, pp. 21-22).

Sin embargo, estos primeros desequilibrios de desafiar desde regiones subterráneas a las fuerzas externas y superpuestas arriba tomaron igualmente amplitud en el terreno académico. Pues, cuatro años más tarde en el Politeama (1888), el Perú se recomponía de aquella memoria colectiva al que Chile lo había sometido años atrás. Por un lado, Manuel González Prada a remitía con un duro discurso que resumía y reflejaba a la vez el fracaso y el quiebre de los líderes políticos durante aquellas trágicas escenas de batalla y combate, el escritor advertía que el indio aún se encontraba con ese mismo peso como en los tiempos de la colonia, desvaneciéndose en él, lo último del hombre: la esperanza (Chang-Rodríguez, 1976).

Desde otro ángulo, Jorge Basadre -quien fuese uno de los historiadores más representativos de la época- avizoraba desde ya, que la ausencia del Estado conduciría a todos aquellos elementos que la componían y eran parte de su estructura, hacia un apocalíptico abismo social (Guarderas M., 2005). Tal augurio no podía no ser extraño, pues todo aseguraba y daba indicio de que lo próximo era real y estaba muy cerca. Puesto que, no era raro que durante esos años después de la guerra binacional entre Perú y Chile, el Estado peruano anduviera con un rostro superficial abatido, con una herencia colonial incrustada en todas las esferas públicas y que en su transcurrir el capitalismo lo iba metabólicamente consumiendo por dentro. Engendrando así, nuevas fuerzas productoras expansivas y de flujos económicos ancorados a actividades endógenas, además de crear una nueva morfología y de relación social con impuestos terrenales de apropiación y despojo (Guibal e Ibáñez, 1987).

En esa consistencia, con una mirada eurocéntrica, proponiendo ideas subcontinentales ideológico-políticos y elementos de fuerza para una renovación de la sociedad peruana ulterior al cataclismo y de la condición que la describía tal cual era (Salcedo, 2014), fueron los recuerdos y las inconsistencias de una clase social confusa y de una latente tristeza la que querían justamente revertir la generación arielista. Es decir, una generación que terminó despertando de entre ruinas y de un nacionalismo doloroso, cuyos planteamientos positivistas del análisis social irrumpieron el ámbito cultural y la vida política. No obstante, como señala Hernández (2000, p. 126), “'ni el Perú oficial’ ni el ‘Perú profundo’ fueron receptivos al despertar de los intelectuales novecentistas". Si bien las explicaciones que se pueden acercar sobre ese comportamiento de no recepción pueden deberse a que posteriormente la generación del centenario ingresó a los terrenos del siglo de manera más agresiva que estos primeros, llegando al término de sepultarlos por completo. Otra hipotética explicación que acompaña, es que la realidad fue más poderosa que esa atmósfera conformada por intelectuales que intentaban reconstruir la más profunda y honda expresión desgarrada por los temblores de la guerra; de manera que, pudo no darse ese acogimiento civil por contractivas despertadas por aquellos escenarios al que el terreno social asistió durante esos años, pues por más que hayan pasado no dejaron de estar casi siempre presentes en la memoria histórica de manera imborrable y como taras en el camino social y del proyecto político republicano. 
A este respecto, los síntomas eran claros, el Perú de esos años era completamente áspero, y quien naciera ahí, tenía que encontrarse con los escombros de una realidad aplastada por el pasado. Así es como se llega a ese punto, de una clara ruptura y distinción, puesto que el Perú de ese entonces, como lo indican Melis, Dessau y Kossok (1971, p. 13), antes de Mariátegui, "era el de Manuel González Prada quien sintetizaba los rasgos progresistas y democráticos del cual el Amauta", años posteriores llegaría a alimentarse desde sus inicios prematuros más catastróficos y completamente complejos y absorbiendo todos aquellos males que reposaban en la República del 20.

Pues, para los años en que Mariátegui se descifraba así mismo y reconocía lo mutable que era la sociedad peruana, se produjeron enormes convulsiones y levantamientos indígenas que fueron inmediatamente reprimidos por fuerzas estatales. Tales insurrectas de componente indígena, sin duda, como expusieran intelectuales del momento y la época, "se debieron a la marginación, al olvido y al despojo de sus tierras" (Flores, 2013, p. 6).

Sobre ese encuentro, la gran convulsión agraria tuvo su eclosión a fines de 1915 e inicios de 1916 en las remotas provincias de Puno, Azángaro. Rumi Maqui, fue el movimiento de esas masas campesinas aparentemente resignadas y vencidas durante años que comenzaron por saltar desde las oscuras formas estructurales agnadas en el sur andino del país. Indignados y sofocados por el poderío terrateniente, rechazaron toda la historia erigida desde la conquista; pues intentaron acabar, ya sean en sus sueños, con aquellas energías sombrías que anunciaban la opresión y el desprecio indígena (Canaza-Choque, Supo, Ruelas y Yabar, 2020).

De esta manera, como ondas sísmicas humanas de disputa territorial entre las economías aclimatadas localmente en los campesinos y los terratenientes, los efectos y otros factores posibilitaron estallidos casi simultáneos y en la misma trayectoria: acabar con las pujanzas del dominio y el control de los señores de la tierra. Esta incómoda situación del que atravesó la República Aristocrática no solo terminó mostrando una imagen nunca antes vista, una muy diferente, una en el que el país y la nación eran otras. Sino que también, la sublevación rural iniciada en las regiones más pobres del altiplano peruano tocó la sensibilidad de otras tantas regiones como Cuzco, Andahuaylas, incluso Ayacucho, también Cailloma y por las alturas de Tacna. En realidad, era todo el sur el que quedó afectado por aquellas olas de reivindicación subterránea (Galindo, 1980).

De lo anterior, según cuenta el sociólogo y antropólogo estadounidense William Stein (2007, pp. 1-4), en los tensos años 20 ¿no era ya el Perú llamado así? el medio rural -aquel espacio peruano poco atendido por el Estado- hasta la fecha había experimentado transformaciones “de proporciones [poco previsibles]. Entonces, también 'las masas indígenas' se habían convertido en algo diferente. [Y] la cuestión del indio se fue transformando en una sociedad que cambió aceleradamente desde espacios y desde prácticas no previstas por nadie". El indio era otro, pues este, había quedado trasmutado por los estresores que lo oprimían. De manera que, junto a estos procesos evolutivos de choque, durante las décadas de 1930 y '40, coincidiendo con esas transformaciones encadena, las nuevas corrientes de pensamiento partieron "de un diagnóstico compartido de la realidad peruana: una sociedad dividida, fragmentada, en la cual un pequeño grupo social, la oligarquía, explotaba y marginaba al resto de la población" (Asensio, 2005, p. 138).

Fue además, justo en ese plano de poseedores y desposeídos territorialmente que la penetración del capitalismo en el Perú introdujo un proceso de relativo dislocamiento en 
unas regiones, pues a la vez que significaba y voceaba la eliminación o la transformación completa de comunidades campesinas, terratenientes, pequeños propietarios, artesanos y comerciantes, también condicionaba el papel a una parcial proletarización temprana y de movilidad potente de la mano de obra, mientras que en otras regiones se reforzaba y recomponía un nuevo proceso catalizador de enfeudamiento campesino más agresivo.

Esta situación significó una sola cosa. Que los sectores populares más sensitivos y medios del que poco o casi nada se discutía en la agenda nacional, fueran movidos por la ira y el dislocamiento social. Así, las movilizaciones de clase impregnadas en los años de 1930, fueron el comienzo de la crisis del sistema oligárquico, y que no finalizó sino en 1968, con la irrupción radical de un proceso de transformaciones económicas, sociales y políticas fraguadas por el autoproclamado Gobierno Revolucionario de la Fuerza Armada (GRFA). Una prolongada decadencia del régimen oligárquico que encontró en las fuerzas populares el motor dinámico de dos figuras y de pensamientos clásicos inconclusos, Haya de la Torre y José Carlos Mariátegui (Cotler, 1980).

\section{Conclusiones}

Antes del cierre del siglo XIX, esta termina con ciertas limitaciones internas de soberanía nacional, pues el escenario configurado postguerra con Chile avizoraban el arrasamiento del Estado peruano y de una sociedad pre-industrial que tenía como mecánica la acumulación de riqueza en dos factores productivos bien expresos: el primero, el control de las fuerzas de trabajo, en tanto que la segunda, la apoderación acumulativa de la tierra a través del despojo. Durante ese contexto, los rezagos del ' 79 aún eran parte de las formaciones estructurales que la sociedad y el cuerpo estatal económicamente asumirían frente a las reforzadas fuerzas del capital extranjero en las dos primeras décadas del siglo XX. Si bien la figura inicial mostrada de un pasado atormentado por las envestiduras de la historia, tuvo esto, la certeza más clara de crear en el presente una aparente atmósfera de resignación y tristeza que acompañaron a los primeros pasos de la República del veinte como aquellas trabas que no dejaron continuar con las promesas hechas por la modernidad.

En efecto, los primeros años del siglo XX fueron parte de esas trasformaciones, puesto que la carga histórica acabó sucumbiendo, más plenamente, a los dispositivos regulatorios del Estado. Pues este último, dentro de una situación crítica posconflicto, flexibilizó el ingreso de capitales foráneos y la formación de espacios públicos con un tejido capitalizador abierto al mercado internacional. De manera que, adyacentemente a ese proceso no tardaron en sentirse los primeros estruendos en el corazón de la tierra, del indígena y de una clase media emergente proletarizada a efectos motivados por esa transición, de que si el cambio era bueno o malo, divisaron entonces enormes oleadas de movilización popular a partir de la indignación o la ira para ajustarse al sistema o de enfrentarse a este en una lucha que encontraría en una vida socialmente telúrica y tradicionalmente amenazada por fuerzas externas colonizadoras. Elementos teóricos de fuerza y de gran calibre incrustados en el Amauta de siempre: José Carlos Mariátegui. 
Referencias bibliográficas

Adrianzén, A. (2011). La izquierda derrotada. En Apogeo y crisis de la izquierda peruana. Hablan sus protagonistas (pp. 45-60). Perú: IDEA Internacional.

Asensio, R. H. (2005). ¿Qué es democracia? El uso de los conceptos pueblo y democracia en los discursos políticos peruanos. En El Estado está de vuelta: desigualdad, diversidad y democracia (pp. 137-158). Lima: IEP.

Canaza-Choque, F. A. (2018a). Educación y desigualdad en el Perú: rupturas y redes de esperanza en el plan de vivir juntos. UCV HACER Rev. Inv. Cult., 7(2), 69-79.

Canaza-Choque, F. A. (2018b). Justicia ambiental vs capitalismo global. Experiencias, debates y conflictos en el Perú. Revista de Investigaciones Altoandinas, 20(3), 369-379.

Canaza-Choque, F. A. (2018c). La sociedad 2.o y el espejismo de las redes sociales en la modernidad líquida. In Crescendo, 9(2), 221-247.

Canaza-Choque, F. A. (2019a). Estado y sociedad al borde del siglo XXI: tensiones y emergencias. Universidad y Sociedad, 11(5), 70-74.

Canaza-Choque, F. A. (2019b). Pluri-versalismo transmoderno decolonial en la crisis civilizatoria: una lectura clave a Grosfoguel. Cátedra Villarreal, 7(1), 17-25.

Canaza-Choque, F. A. (2020). La gran estampida. Humanos caminando en la modernidad líquida. Encuentros. Revista de Ciencias Humanas, Teoría Social y Pensamiento Crítico., (12), 127-145.

Canaza-Choque, F. A., \& Huanca-Arohuanca, J. W. (2018). Perú 2018: hacia una Educación Intercultural Bilingüe sentipensante. Sciéndo. Ciencia Para El Desarrollo, 27(4), 515-522.

Canaza-Choque, F. A., Supo, F., Ruelas, D., \& Yabar, P. S. (2020). El regreso del Puma Indomable. Neoliberalismo y las luchas sociales desde la Escuela Pública en el Sur del Perú. Revista Conrado, 16(74), 154-161.

Castro, A. (2006). Filosofía y política en el Perú. Estudio del pensamiento de Víctor Raúl Haya de la Torre. Lima: PUCP.

Chang-Rodríguez, E. (1976). El ensayo de Manuel González Prada. Revista Iberoamericana, 239250.

Cotler, J. (1980). Democracia e integración nacional. Lima: IEP.

D'Allemand, P. (1994). Las contribuciones de Mariátegui a la crítica latinoamericana. Thesaurus Boletín del instituto Caro y Cuervo, 49(3), 449-49o.

Escobedo, J. (2014). Paradigma y método de José Carlos Mariátegui en la investigación social. Puno: Editorial UNA-Puno.

Flores, J. H. (2013). El pensamiento de José Carlos Mariátegui. Teoría y Praxis, (9), 76-105.

Galindo, A. F. (1980). La Agonía de Mariátegui. La polémica con la Komintern. Lima: DESCO.

Gomes, M. (2007). Mariátegui o el discurso de la piedra: un análisis genológico de los Siete ensayos. Cuadernos del CILHA, 162-174.

Gonzales, O. (2011). La amistad en Mariategui. En Simposio internacional 7 ensayos, 80 años. Mi sangre en mis ideas (pp. 57-75). Lima: Ministerio de Cultura.

Guarderas, M. d. (2005). Nación y Territorio en el Perú. En Aula Magna 2005: El Perú que debemos ganar: 2006-2011, (pp. 1-16). Lima. PUCP

Guibal, F., \& Ibáñez, A. (1987). Mariategui Hoy. Lima: Tarea.

Hernández, M. (2000). ¿Es otro el rostro del Perú? Identidad, diversidad y cambio. Lima: AGENDA. 
Huanca-Arohuanca, J. W., \& Canaza-Choque, F. A. (2019). Puno: educación rural y pensamiento crítico. Hacia una educación inclusiva. Revista Helios, 3(1), 97-108.

Klarén, P. F. (2007). El tiempo del miedo (1980-2000), la violencia moderna y la larga duración en la historia peruana. En Historizar el pasado vivo en América Latina, ed. Anne Pérotin-Dumon. Santiago

Mariátegui, J. (1997). José Carlos Mariátegui y el Continente Asiático (1923-1930). Lima: Clenala.

Mariátegui, J. C. ([1928] 2007). 7 ensayos de interpretación de la realidad peruana. Ayacucho: Biblioteca Ayacucho.

Mariátegui, J. C. (2010). La tarea americana. Buenos Aires: Prometeo Libros.

Mariátegui, J. C., Flores Galindo, A., \& Portocarrero Grados, R. (1989). Invitación a la vida heroica: antología. Lima: Instituto de Apoyo Agrario.

Melis, A., Dessau, A., \& Kossok, M. (1971). Mariátegui: tres estudios. Lima: Amauta.

Miró, C. (1989). Mariategui el tiempo y los hombres. Lima: Amauta.

Quijano, A. (2012). Ser el cuarto Mariátegui. En José Carlos Mariátegui. Formación, contexto e influencia de un pensamiento. Lima: Universidad Ricardo Palma.

Ramos, J. A. (1973). De Mariátegui a Haya de la Torre. Archivo Chile,Web del Centro de Estudios "Miguel Enriquez", CEME, 1-18.

Salazar-Bondy , A. (2016). La cultura de la dominación. En Antología del pensamiento crítico peruano contemporáneo (pp. 175-196). Buenos Aires: CLACSO.

Salcedo, J. S. (2014). Realidad nacional: una interpretacion a su estudio cientifico-I. Trujillo: IQRA Ediciones.

Stein, W. W. (2007). Peruanicemos al Perú: José Carlos Mariátegui y José María Arguedas. CEME: Centro Estudios Miguel Enríquez, 1-35.

Tarazona, R. r. (2011). A ochenta años del septimo ensayo . En Simposio internacional 7 ensayos, 80 años. Mi sangre en mis ideas (pp. 111-118). Lima: Ministerio de Cultura.

C Los autores. Este artículo es publicado por la Horizonte de la Ciencia de la Unidad de Posgrado de la Facultad de Educación de la Universidad Nacional del Centro del Perú. Este es un artículo de acceso abierto, distribuido bajo los términos de la Licencia Atribución-No Comercial 4.0 Internacional.(https://creativecommons.org/licenses/by-nc/4.o/), que permite el uso no comercial y distribución en cualquier medio, siempre que la obra original sea debidamente citada. 